\title{
Cross-category structure in semantic memory
}

\author{
DOUGLAS J. HERRMANN \\ Hamilton College, Clinton, New York 13323 \\ and \\ EDWARD J. SHOBEN, JOSEPH R. KLUN, and EDWARD E. SMITH \\ Stanford University, Stanford, California 94305
}

\begin{abstract}
In Experiment I, subjects made similarity judgments about all 56 category terms listed in the Battig and Montague (1969) norms. These judgments were then subjected to a hierarchical clustering analysis. Experiment II demonstrated that the relations among the category labels are very similar to the relations among the high dominance exemplars of these categories. Experiment III showed that the distances between the category terms in the hierarchical clustering analysis could predict RTs in a same-different paradigm.
\end{abstract}

Recent studies have used the Battig and Montague (1969) category norms in an attempt to delineate the semantic structure of particular domains (e.g., Rips, Shoben, \& Smith, 1973). These norms present, for each of 56 categories, a dominance ordering of the different instances of that category, where the dominance of an instance is the number of subjects who listed it as an exemplar of that category. Thus these norms provide possible information about within-category structure, but say nothing about between-category structure. Yet the similarity relations between various categories can be of critical concern in semantic memory research. To illustrate, consider the same-different task introduced by Schaeffer and Wallace (1970). A subject is presented a word pair and is instructed to respond "same" if both words are drawn from the identical category (e.g., hawk, dove), and "different" otherwise (e.g., howk, salmon). Researchers have been interested in the time needed to respond "different" as a function of the similarity of the two words; but to measure this similarity accurately, it is often important to know something about the similarity of the two categories that the words were drawn from (birds and fish, in the above example).

The main purpose of the present paper is to provide measures of between-category similarity for all 56 categories used in the Battig and Montague (1969) norms. Toward this end, we performed a hierarchical clustering analysis of these categories, and then validated our analyses by means of two follow-up experiments. The similarity judgments used as input to the clustering analysis were obtained by asking subjects to sort the 56 category names into groups on the basis of common meaning, a procedure recently used by Miller (1967, 1969).

The authors are indebted to Lance $J$. Rips and James $M$. Waters for invaluable assistance and advice at various stages of the investigation. Part of this research was condicted while the first author was on a Social Science Research Council Fellowship at Stanford University. Requests for reprints should be sent to Douglas J. Herrmann. Department of Psychology, Hamilton College, Clinton. New York 13323.

\section{EXPERIMENT I}

\section{Method}

Materials and procedure. Computer printouts listed the 56 categories in the Battig and Montague (1969) norms. Each printout presented a different random ordering of these categories. Alongside of each category on the printout was its category number. Each subject was given a computer printout, directed to examine the list of categories, and to decide which categories, if any, shared some meaning. The subject then recorded by category number those groups of categories which were perceived to share a common meaning. Each category was only permitted to be used in one group. A category which held nothing in common with other categories was to be listed separately, i.e., a "group" containing one item.

Subjects. One hundred and twenty-three subjects participated in the experiment, with 100 of them fulfilling a course requirement.

Analysis. A similarity matrix was derived for all 56 categories by summing the number of subjects who grouped a certain category with each of the remaining categories. Thus, the similarity matrix consisted of 1540 cells. The matrix was then subjected to a clustering analysis with Johnson's (1967) hierarchical clustering routine.

\section{Results}

The results of the clustering analysis (diameter method) are shown in Figure 1. Examination of the figure shows that subjects tended to group categories in one of the six major branches. The branches can be labeled with names suggested by categories in a branch, e.g., the third branch from the top deals with a biological taxonomy of living things, while the fifth branch from the top involves matters of concern to scientists. Inspection of the results in Figure 1 further indicated that the clustering solution was consistent with theories assuming hierarchical structure in semantic memory (e.g., Collins \& Quillian, 1969), in that Johnson's clustering statistic was significant at the .05 level or better for $85 \%$ of all recovered clusters. Clearly the null hypothesis of random sorting across subjects can be discarded. 


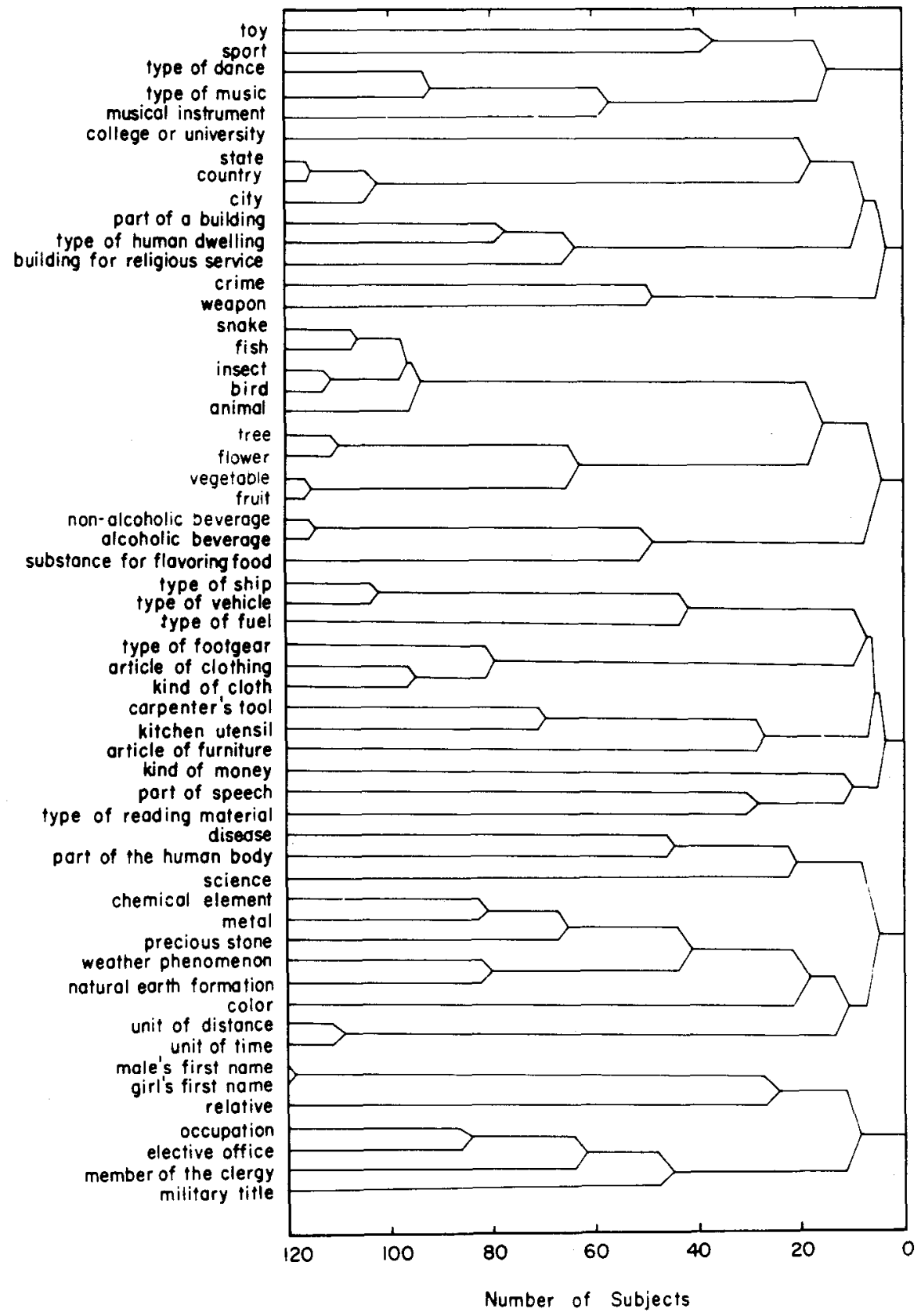

Figure 1. Tree graph of cluster analy sis (diameter method) applied to data on 56 categories sorted by 123 subjects.

\section{EXPERIMENT II}

It is commonly held that when subjects process instances of a category they also covertly process the category label as well (Bousfield, 1953; Shuell, 1969). If this notion has any validity, then the present sorting of category labels should be able to predict how subjects might sort instances of these categories. To test this hypothesis, the above results of the category-sorting experiment were compared to results of a task in which subjects had to sort instances for 18 out of the 56 categories.

\section{Method}

Twelve subjects participated in the instance-sorting task as part of a learning experiment (Herrman \& McLaughlin, 1974) whose purpose was not germane to the present study. There were three lists (A, B, and C) of instances from 18 categories. These categories were: military title, cloth, kitchen utensil, part of speech, furmiture, elected office, alcoholic beverage, carpenter's tool, substance for flavoring food, weather phenomenon, chemical element, money, bird, nonalcoholic beverage, science, footwear, tree, and fish. The three lists differed only in which instances represented each of the 18 categories; no two lists contained the same exemplar of a category. All instances were highly typical of the 18 categories with a mean frequency in the Battio and Montague (1969) norms of 273 out 
of a possible 442 . Each of three lists, A, B, and C, was sorted by four subjects. Subjects were required to sort instances into at least two and no more than seven groups (cf. Mandler, 1967).

\section{Results and discussion}

A similarity matrix was derived for the instance-sorting data according to the 18 categories to which the instances belonged; thus, the matrix contained 153 cells. A correlation was then performed on the two matrices, one matrix being the instance-sorting data and the other matrix being category-sorting data for the 18 relevant categories. The correlation between the two matrices was $.69(\mathrm{p}<.001 ; \mathrm{df}=152)$.

From this correlation it is evident that subjects sort category labels and typical instances of these categories in a very similar manner. In fact, because of procedural differences in sorting, the present correlation undoubtedly underestimates the true degree of congruence between the two sortings. This congruence can be explained in several possible ways. First, when subjects judge the similarity of instances, they may process category meaning as well (Bousfield, 1953). Conversely, subjects may refer to some typical exemplars of a category when they are asked to sort that category label (Rosch, 1973). A further possibility is that both category labels and instances are sorted on the basis of semantic features. Since the instances used were very typical of their categories, these instances undoubtedly share many features with their superordinates (Rips et al., 1973; Smith, Shoben, \& Rips, 1974; Smith, Rips, \& Shoben, 1974). Items which shared many semantic features would be sorted in similar fashion.

\section{EXPERIMENT III}

One task which has been used to study semantic memory is the same-different categorization task mentioned in the introduction. Recall that in this task, subjects are presented with a pair of words and are required to determine if both words belong to the same category or not. Using this paradigm, Schaeffer and Wallace (1970) demonstrated that the time required to respond "different" increased with the semantic similarity of the two items in the test pair. Here it was assumed that two items were similar (e.g., robin, dog) when their direct superordinates (e.g., birds and mammals) were themselves dominated by the same superordinate (e.g., animal); otherwise the items were considered dissimilar. Thus, the results of Schaeffer and Wallace indicate the usefulness of determining the similarity between items in terms of the similarity between their superordinates. The results of Experiment I offer a means by which the Schaeffer and Wallace approach may be extended. Specifically, one may use our hierarchical analysis to determine varying degrees of similarity among the superordinates of the instances in a "different" item. And this degree of similarity would be expected to be a major determinant of "different" RT.

\section{Method}

Subjects. Sixteen students from Hamilton College and Kirkland College were paid $\$ 2$ for participation. All subjects were right-handed. One additional subject was tested in the task but was dropped from the analysis for making too many errors ( $31 \%$ errors).

Apparatus. A three-channel tachistoscope (Iconix, Model 6137) presented a white prepost field in the first channel, a fixation field in the second channel, and the word pair in the third channel. Each word in the pair was typed in uppercase letters, and one word was presented above the other. The response apparatus consisted of two microswitches which were held in each hand. Latencies were measured to an accuracy of $\pm 1 \mathrm{msec}$.

Procedure. Each subject was tested individually. Subjects were instructed to respond "same" if both test words were from the same category and "different" otherwise. Half of the subjects held the "same" button in the right hand and half held it in the left hand, and vice versa for the "different" button.

The subject was presented with five practice pairs followed by 120 test pairs. Sixty test pairs required a "same" response and 60 a "different" response. The test pairs were presented in blocks of 30 with the pairs randomly ordered within a block with respect to experimental conditions. The experimental variables were the type of response and the hierarchical distance between the categories of a "different" pair. The latter was taken from Figure 1, and this distance could be "close," "međium," or "far." A close distance was defined as any two adjacent categories which are joined by a single node in Figure 1 and whose node is between 80 and 120 subjects sorting those categories together in the figure. A medium distance was defined as any two categories which are joined by at least two nodes and which are within the same major branch (out of six major branches) in Figure 1. A far distance was defined as any two categories which are in two different major branches in Figure 1. All categories in Figure 1 were represented at least once and no more than twice in "same" pairs and no more than three times in "different" pairs. Instances representing categories in the pairs were selected from the Battig and Montague (1969) norms; the mean frequency of these instances was 200 . Word length and frequency were matched across "same" and "different" pairs, and across close, medium, and far conditions.

\section{Results and discussion}

The mean of median correct reaction times was $1430 \mathrm{msec}$ for "same" pairs; $1927 \mathrm{msec}$ for close, "different" pairs; 1570 msec for medium, "different" pairs; and 1474 msec for far, "different" pairs. "Same" RT was significantly faster than close and medium "different" pairs $[\mathrm{t}(15)=4.25, \mathrm{p}<.01$, $\left.S E_{M}=117 \mathrm{msec}\right]$ and $t(15)=2.67, p<.02$, $\left.\mathrm{SE}_{\mathrm{M}}=52 \mathrm{msec}\right]$, respectively; but there was no significant difference between "same" RT and far, "different" RT $\left[\mathrm{t}(15)=.66, \mathrm{SE}_{\mathrm{M}}=65 \mathrm{msec}\right]$. The tendency for "different" RT to decrease as category distance (a measure of dissimilarity) increased was confirmed by an analysis of variance, according to Clark (1973), $\quad\left[F(2 / 33)=6.47, \quad p<.01, \quad M_{e}=4.67\right] . \quad A$ 
Newman-Keuls test showed that the difference in RT between close and medium "different" pairs was significant, $p<.01$; the difference between close and far pairs was also significant, $p<.01$, but the difference between medium and far pairs turned out to be insignificant.

For "different" pairs, errors decreased as distance increased, and generally mirrored the RT data. The error rate for close "different" pairs was $29.4 \%$, while medium and far "different" pairs had error rates of $7.8 \%$ and $2.2 \%$, respectively. An analysis of variance indicated that these errors differed significantly from each other $\left[F(2 / 79)=5.66, p<.01, \quad \mathrm{MS}_{\mathrm{e}}=.32\right]$. Errors also occurred on $7.1 \%$ of the "same" trials.

Further inspection of error rates of specific test pairs indicated that four of them were classed erroneously by a majority of subjects. All four pairs were such that, based on category membership, we had decided they were "different" pairs, e.g., train-rowboat, while most of our subjects thought they were drawn from the same category.

The results of this experiment, then, indicate that the difficulty of "different" decisions varies directly with the semantic similarity of the items in the test pair. Very dissimilar items resulted in a fast "different" RT, whereas relatively similar items required a longer RT. This replicates the finding of Schaeffer and Wallace (1970) and, more importantly, demonstrates that the proximity measures of categories obtained in Experiment I can predict latencies in a task using exemplars of those categories.

\section{REFERENCES}

Battig, W. F. Montague, W. E. Category items for verbal norms in 56 categories: A replication and extension of the
Connecticut category norms. Journal of Experimental Psy chology, 1969, 80 (3, Pt. 2).

Bousfield, W. A. The occurrence of clustering of the recall of randomly arranged associates. Journal of General Psychology, $1953,49,229-240$.

Clark, H. H. The language-as-fixed-ffect fallacy: A critique of language statistics in psy chological research. Journal of Verbal Learning and Verbal Behavior, 1973, 12, 335-359.

Collins, A. M.. \& Quillian, $M$. $R$. Retrieval time from semantic memory. Journal of Verbal Learning and Verbal Behavior, $1969,8,240-247$.

Herrmann, D. J.. \& McLaughlin, J. P. Recognition latency for a subjectively organized list. Journal of Experimental Psy chology, 1974, 102, 888-889.

Johnson, S. Hierarchical clustering schemes. Psychometrika, $1967,32,241-254$.

Mandler, G, Organization and memory. In K. W. Spence \& J. T. Spence (Eds.), The psychology of learning and motivation: Advances in research and theory. New York: Academic Press, 1967.

Miller, G. A. Experimental methods in the study of semantics. In D. L. Arm (Ed.), Joumeys in science: Small steps-great strides. Albuquerque: University of New Mexico Press, 1967.

Miller, G. A. A psychological method to investigate verbal concepts. Journal of Mathematical Psychology, 1969, 6, 169-191.

Rips, L., Shoben, E., \& Smith, E. Semantic distance and the verification of semantic relations. Journal of Verbal Learning and Verbal Behavior,1973, 12, 1-20.

Rosch, E. On the internal structure of perceptual and semantic categories. In T. E. Moore (Ed.), Cognitive development and acquisition of languages. New York: Academic Press, 1973.

Schaeffer, B., \& Wallace, R. Semantic similarity and the comparison of word meanings. Journal of Experimental Psychology, 1970, 86, 144-152.

Shuell, $T$. $J$. Clustering and organization in free recall. Psychological Bulletin, 1969, 72, 353-374.

Smith, E. E., Rips, L. J., \& Shoben, E. J. Semantic memory and psyehological semantics. In $G$. $H$, Bower (Ed.), The prychology of learning and motivation: Advances in research and theory. New York: Academic Press, 1974.

Smith, E. E., Shoben, E. J., \& Rips, L. J. Structure and process in semantic memory: A featural model for semantic decisions. Psy chological Review, 1974, 81, 214-241.
(Received for publication January 27, 1975. Revision received March 24, 1975.) 